\title{
HISTORIOGRAFÍA LITERARIA LATINOAMERICANA COLONIAL- CONTEMPORÁNEA (1973-1993) DE JOSÉ ANADÓN. INSTITUCIÓN DISCIPLINAR Y DEVENIR HISTÓRICO.
}

\section{Hugo Herrera Pardo}

Prologado por el erudito colonialista Nelson Osorio Tejeda, Historiografía literaria latinoamericana colonial-contemporánea (19731993) compila veinticuatro trabajos elaborados a lo largo de dos décadas por el estudioso del periodo colonial americano José Anadón. El conjunto de textos antologado destaca de entrada por su diversidad formal; se incluyen en la selección artículos, notas, entrevistas, presentaciones a simposios, prólogos, entre otros, que dan cuenta del sostenido proyecto investigativo de dominio filológico y hasta paleográfico que Anadón ha desarrollado en su extensa carrera académica. En este sentido, resulta innegable su aporte al trabajo de archivo y sus cotejos de escritos para contribuir a ediciones definitivas, específicamente con respecto a algunos documentos y figuras históricas particulares. En concreto, sus estudios sobre Juan Barrenechea y Albis, Juan Mogrovejo de la Cerda, Francisco Loubayssin de la Marca y, por sobre todo, Francisco Núñez de Pineda y Bascunán, debieran constituir por su dominio filológico fuentes ineludibles en las respectivas bibliografías sobre estos autores y sus principales escritos conservados. No obstante lo anterior, y puesto que las dos décadas que componen el marco temporal de este volumen recopilatorio convergen, en gran parte, con la transformación del campo de los estudios coloniales latinoamericanos contemporáneos -signada en torno a la década de 1980-, la evaluación del libro es cruzada de modo tangencial por las operaciones de elucidación y contrastación.

De acuerdo a una apreciación de Roger Chartier (Escribir las prácticas), en las últimas décadas tres conceptos permitieron renovar la reflexión de las ciencias humanas y sociales. A saber, estos conceptos son los de discurso, práctica y representación. No es esta la oportunidad para someter a mayor escrutinio a aquella aseveración, por ejemplo a

Profesor del Departamento de Humanidades de la Universidad Andrés Bello. Correo electrónico: hugo.herrera.pardo@gmail.com 
partir de los silenciamientos de autores, categorías y discusiones que el planteamiento de Chartier solapadamente encubre, en pos de legitimar un debate que en el contexto de su libro rastrea la proposición de aquellas tres categorías en relevantes pensadores franceses de las décadas del sesenta y setenta (Foucault, De Certeau, Marin). Sin embargo, sería exagerado no reconocer la presencia e importancia de las tres nociones aludidas en los debates al interior tanto del giro lingüístico como del giro cultural que tanto marcaron y definieron el desarrollo de las ciencias humanas y sociales durante la segunda mitad del siglo pasado. Y dentro de esa reconfiguración, una de las disciplinas que mayormente se vio revitalizada fueron los Estudios Coloniales, no solo Latinoamericanos sino que de modo transversal a toda disciplina enfocada a la investigación colonial en alguna de las zonas geo-culturales que experimentaron el fenómeno de la colonización. Y esto debido fundamentalmente a que los conceptos de discurso, práctica y representación posibilitaron nuevos modos desde donde pensar la relación entre lenguaje y poder, o en otros términos, proporcionaron encrucijadas teóricas más complejas desde donde analizar el fenómeno de la dominación y la construcción social de los discursos, estableciendo con ello otros marcos para afrontar la significación de las prácticas discursivas, sus imposiciones de sentido, sus diversas relaciones como estrategias subjetivas e institucionales. Permitieron, en definitiva, una profunda actividad reflexiva en torno a la relación existente entre ciertos procedimientos semióticos y textuales específicos y el fenómeno del colonialismo en general. Bajo este marco, y a pesar del acercamiento a autores indígenas presentado en algunos de los últimos trabajos compilados en este volumen, el proyecto investigativo de José Anadón permaneció bien cercano a los criterios que fundaron la occidentalizante tradición selectiva de los estudios coloniales hispanoamericanos, y que Walter Mignolo en uno de sus textos más conocidos sobre la reconfiguración del campo en cuestión ("La lengua, la letra, el territorio. O la crisis de los estudios literarios coloniales") definiera como los criterios idiomático, literario y cultural. Por motivos de extensión, en lo sucesivo comentaré solo dos de las expresiones que encontramos en este libro con respecto a la aseveración anterior, las cuales son su asunción de lo latinoamericano alrededor de lo criollo y su persistencia en la discusión sobre los orígenes de la novelística americana en textos producidos durante diversos momentos del periodo colonial y que claramente exceden ese particular tipo discursivo. 
En el primer caso expresivo, y siendo coincidente el tramo temporal que enmarca esta selección de trabajos con la crisis del nacional-populismo en América Latina, la irrupción violenta de las dictaduras militares como preservadoras y actualizadoras del colonialismo interno nacionalista, las transformaciones económicas que dejaron atrás los modelos dominantes hacia mediados de siglo XX, las guerras de guerrillas que acontecieron en América Central y del Sur y, con todo ello, el consecuente desplazamiento de la centralidad de la letra y los letrados en el discurso latinoamericanista, Anadón sigue sosteniendo la idea del "advenimiento de una conciencia propia que se manifiesta claramente en "lo criollo" (412). Si bien, a renglón seguido, argumenta que "Esa conciencia no es pura sino híbrida: tiene mezcla de europeo, más variados elementos indígenas y africanos, $\mathrm{u}$ otros" (412), lo que realiza a fin de cuentas es articular hegemónicamente el campo significante de lo latinoamericano en torno al sector "criollo blanco, intelectual, hispanizante", sin reconocer los quiebres y fracturas de un largo proceso histórico que, y en un trabajo escrito a comienzos de los noventa, aún persiste en reconocer como una "coherencia interna evolutiva", al modo de las historias literarias más relevantes de las décadas del cuarenta y cincuenta del siglo pasado, como los trabajos de Pedro Henríquez Ureña y Antonio Candido. Al sublimar por medio de una historia rectilínea y teleológica importantes diferencias al interior de culturas regionales tradicionales, esta perspectiva tomada por Anadón conduce a un importante efecto político. En concreto, subsumir en una articulación hegemónica a grupos sociales contrahegemónicos o de hegemonía alternativa trae como consecuencia algo que Neil Larsen ha expresado para un caso posterior dentro de la historia latinoamericana: "La cultura en sí deviene el límite deshistorizador y naturalizador de lo que podría ser, contrariamente, la emergencia de una contra-racionalidad concreta directamente opuesta a la racionalidad del estado" (Modernism and hegemony 64). Por tanto, la heterogeneidad de aquella "conciencia propia" defendida por Anadón resulta superficial, desproblematizada, debido a que no produce alguna tensión relevante frente al discurso de los universales nor-atlánticos, para tomar una expresión de RolphMichel Trouillot.

En relación al segundo caso expresivo, una parte considerable del trabajo de José Anadón con los textos de los autores indicados al inicio (Núñez de Pineda, Barrenechea y Albis...) todavía apunta a participar 
en la discusión sobre los hitos de origen de la novela hispanoamericana, cuando los avances teóricos que transformaron el campo de los estudios coloniales posibilitaron desestabilizar las tipologías textuales de la tradición occidental, permitiendo una crítica epistemológica a la pertenencia de tales categorías al contexto de las producciones escritas en el "Nuevo Mundo", discusión en la que sobre todo el Cautiverio feliz podría llegar a ser (y ciertamente así ha sucedido) relevante y efectiva. En cambio, el esfuerzo de Anadón se concentra en mantener lo forzado que resulta el intento de hacer calzar textos complejamente heterogéneos en estructuras dadas, establecidas, asumiendo irrevocablemente la lógica de separación categorial constituyente del pensamiento occidental y que muchos de los textos coloniales colocan en entredicho, a partir de las presiones contextuales que sobredeterminan sus condiciones de producción. En definitiva, se trata nuevamente de una consideración teleológica del tiempo que en su intención de enfatizar la particular "lógica histórica interna" de un tipo discursivo específico termina obliterando el horizonte de la multiplicidad que ofrecen los textos coloniales, despotenciando así sus sentidos de discontinuidad y heterogeneidad para la construcción de una historia diferencial efectiva.

En suma, Historiografía literaria latinoamericana colonialcontemporánea (1973-1993), constituye un volumen cuyo valor descansa en un dominio estrictamente disciplinar: sus cotejos de escritos y trabajo de archivo permitieron reconstruir biografías de complejo acceso, elucidar enrevesados problemas textuales y permitir ediciones críticas de primer orden para textos significativos dentro de la historia americana. Sin embargo, constituye un trabajo investigativo que permanece distante con respecto a las líneas de avanzada de un periodo de transformación radical para la imaginación histórica y crítica sobre la experiencia colonialista, las cuales, en muchos casos, excedieron los límites disciplinares para avanzar hacia discusiones políticas, epistemológicas y ontológicas de notable aportación para algunos movimientos sociales que actualmente movilizan el continente. 


\section{Obras citadas}

Anadón, José. Historiografía literaria latinoamericana colonialcontemporánea (1973-1993). México D.F.: Seminario de Cultura Mexicana, 2015.

Chartier, Roger. Escribir las prácticas. Foucault, de Certeau, Marin. Trad. de Horacio Pons. Buenos Aires: Manantial, 1996.

Larsen, Neil. Modernism and Hegemony, Minneapolis, University of Minnesota Press, 1990. 